\title{
Habitat selection and foraging site fidelity in Caspian Terns (Hydroprogne caspia) breeding in the Baltic Sea
}

\author{
Martin Beal*, Patrik Byholm, Ulrik Lötberg, Tom J. Evans, \\ Kozue Shiomi \& Susanne Åkesson*
}

M. Beal, Department of Biology, Center for Animal Movement Research, Lund University, Lund, Sweden \& Rua do Olival 84, 3, 1200-742, Lisbon, Portugal (present address)

* Corresponding author's e-mail: martinbeal88@gmail.com

P. Byholm, Organismal \& Evolutionary Biology, PO Box 65, FI-00014, University of Helsinki, Finland \& Novia University of Applied Sciences, Raseborgsvägen 9, FI-10600 Ekenäs, Finland

U. Lötberg, BirdLife Sweden, Stenhusa Gård, 38662 Mörbylånga, Sweden

T.J. Evans, Department of Biology, Center for Animal Movement Research, Lund University, Lund, Sweden \& Marine Scotland Science, Marine Laboratory, 375 Victoria Road, Aberdeen, AB11 9DB, UK (present address)

K. Shiomi, Department of Biology, Center for Animal Movement Research, Lund University, Lund, Sweden \& Frontier Research Institute for Interdisciplinary Sciences, Tohoku University, Japan (present address)

S. Akesson, Department of Biology, Center for Animal Movement Research, Lund University, Lund, Sweden*Corresponding author's e-mail: susanne.akesson@biol.lu.se

Received 9 February 2021, accepted 6 October 2021

Habitat preferences and foraging strategies affect population-level space use and are therefore crucial to understanding population change and implementing spatial conservation and management actions. We investigated the breeding season habitat preference and foraging site fidelity of the under-studied and threatened, Baltic Sea population of Caspian Terns (Hydroprogne caspia). Using GPS devices, we tracked 20

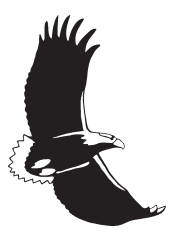
adult individuals at two breeding colonies, in Sweden and Finland, from late incubation through chick-rearing. Analyzing foraging movements during this period, we describe trip characteristics for each colony, daily metrics of effort, habitat use, and foraging site fidelity. We found that daily time spent away from the colony increased throughout the season, with colony-level differences in terms of distance travelled per day. In general, terns selected shallow waters between 0-5 meters in depth with certain individuals using inland lakes for foraging. We show, for the first time, that individual Caspian Terns are faithful to foraging sites throughout the breeding season, and that individuals are highly repeatable in their strategies regarding foraging site fidelity. These results fill important knowledge gaps for this at-risk population, and extend our general knowledge of the breeding season foraging ecology of this widespread species. 


\section{Introduction}

Foraging ecology is central to animal biology, influencing individual fitness and shaping the spatial distributions of animal populations (Norberg, 1977; Olsson \& Bolin, 2014). During the breeding season, the foraging ecology of colonial birds is constrained by the responsibility of raising young at a fixed location and potential competition for prey (Ricklefs, 1990). Studying the movement patterns of breeding adults can reveal what subset of the surrounding landscape is available to them for foraging and the strategies used to meet the demands of rearing chicks in a competitive context (Wakefield et al., 2009). Habitat preferences and foraging strategies affect population-level space use and are therefore crucial to understanding broader population change and implementing effective area-based conservation and management action (Donazar et al., 1993).

The foraging ecology of seabirds often varies across populations, reflecting potential differences in biotic and abiotic processes (Torres et al., 2015). Caspian Terns (Hydroprogne caspia) occur in freshwater and marine coastal ecosystems around the world and despite this wide range, their populations are often disjunct (Craig \& Larson, 2017). While there are a number of studies concerning the foraging ecology of Caspian Terns (e.g., Dunlop \& McNeill, 2017; Lyons et al., 2005; Sirdevan \& Quinn, 1997), there remains a dearth of information on many populations, including the Baltic Sea where the species underwent a serious decline in the 1970s and is conservation-listed in the region (HELCOM Red List Bird Expert Group, 2013). Caspian Terns are considered generalist piscivores, however they are not habitat generalists and are often described as preferring 'shallow water' (Koli \& Soikkeli, 1974; Lyons et al., 2005). Previous work in the Columbia River estuary in the US showed that certain habitats there, such as ocean jetties and the main river channel, are selected and avoided, respectively (Lyons et al., 2007). This suggests that Caspian Terns indeed prefer shallower water for foraging (Dunlop \& McNeill, 2017), however what range of water depths are utilized relative to their availability and how individuals may vary in their habitat use remains unclear.
The energetic demands associated with nesting change across the breeding season, from incubation to chick-rearing, and as chicks grow (Humphreys et al., 2006). Previous work on Caspian Terns identified limited differences between breeding stages in terms of foraging trip characteristics like maximum distance travelled and trip duration (Anderson et al., 2007), suggesting minimal changes in foraging effort throughout breeding. However, foraging effort may not be fully captured by these per trip metrics, as Caspian Terns take multiple trips per day. To better understand how movements related to foraging effort vary across the breeding season, per day metrics of time spent and distance travelled on foraging trips should also be investigated.

When resources are patchy yet predictable in space, individuals may use prior knowledge of sites containing prey to increase foraging success and reduce competition (Weimerskirch, 2007). Termed 'individual foraging site fidelity', this phenomenon can arise through different mechanisms, including habitat or prey specialization, and through avoidance or active exclusion of conspecifics (i.e. territoriality) (Piper, 2011; Wakefield et al., 2015). Whether populations show foraging site fidelity is relevant to conservation and management, as the persistence of site use may indicate the efficacy of site-based management strategies (e.g. protected area establishment; Augé et al., 2018). Although foraging site fidelity depends on spatio-temporal prey dynamics, gathering direct information on prey fields remains a challenge, especially in aquatic systems (Birt et al., 1987). In recent years, individual-based tracking data has been used to infer foraging site fidelity in an increasing number of seabird species (Ceia et al., 2014; Irons, 1998; Wakefield et al., 2015). While foraging site fidelity has been described in a number of other larid species (Irons, 1998; Nisbet, 1983), only anecdotal evidence exists to suggest that Caspian Terns re-visit foraging sites during breeding (McNicholl, 1990).

We use GPS-tracking data collected during the breeding period from two colonies of Caspian Terns in the Baltic Sea to investigate the foraging ecology of this under-studied population. First, we describe the foraging trip characteristics of each colony to provide general reference points for 
comparison with other colonies of this widespread species. Then, we test whether breeding Caspian Terns change their foraging effort as nesting progresses, by modelling the daily time spent on foraging trips and total distance travelled per day. Next, we quantify the habitat use of terns from each colony, to describe the range of seawater depths they use on foraging trips as well as the degree to which they utilize freshwater lakes for foraging. We then test whether terns may show foraging site fidelity during breeding by comparing the spatial overlap of weekly home ranges to that of a null distribution produced under the assumption that individuals do not re-visit sites more than expected at random. Finally, we examine whether the rate of foraging site re-visitation changes predictably across the weeks of nesting and whether individual terns are repeatable (i.e., consistently differ) in the degree of site fidelity shown between weeks.

\section{Material and methods}

\subsection{Study sites and device deployment}

We studied two breeding colonies located in the Gulf of Bothnia in the Baltic Sea, on the islands of Norra Stenarna (hereafter 'Stenarna'), in
Sweden $\left(60.63^{\circ} \mathrm{N}, 17.92^{\circ} \mathrm{E}\right)$, and Gubbstenen, in Finland $\left(62.50^{\circ} \mathrm{N}, 21.10^{\circ} \mathrm{E}\right)$ (Fig. 1). The colony on Stenarna is one of the largest in the Baltic, with 110 pairs breeding there during the study periods in 2013 and 2014 and the colony on Gubbstenen hosted 78 breeding pairs during work there in 2016.

At Stenarna, 7 birds were fitted with 7.5 g University of Amsterdam Bird Tracking System GPS-Loggers (model: 2CDSe; Bouten et al., 2013) in 2013 and 2014, respectively. At Gubbstenen, one bird was fitted with a $7 \mathrm{~g}$ Ecotone Telemetry Sterna UHF GPS-logger in 2015, and 5 birds with 13 g Ecotone Telemetry UHF GPS-loggers (model: Harrier-L) in 2016. The tracking devices relay information to a remote base station, one of which was placed at the center of each colony to receive data when the birds approached the island. The individual from 2015 continued transmitting data through the 2016 breeding season, with only data from the latter year being analyzed in the present study. All 20 birds captured were breeding adults captured at the nest using either walk-in cage traps with a trip wire-release door, or spring net traps with a trip wire that releases the spring and folds the net over the nest; all loggers constituted $<3 \%$ of the body weight of tagged individuals (see Supplementary

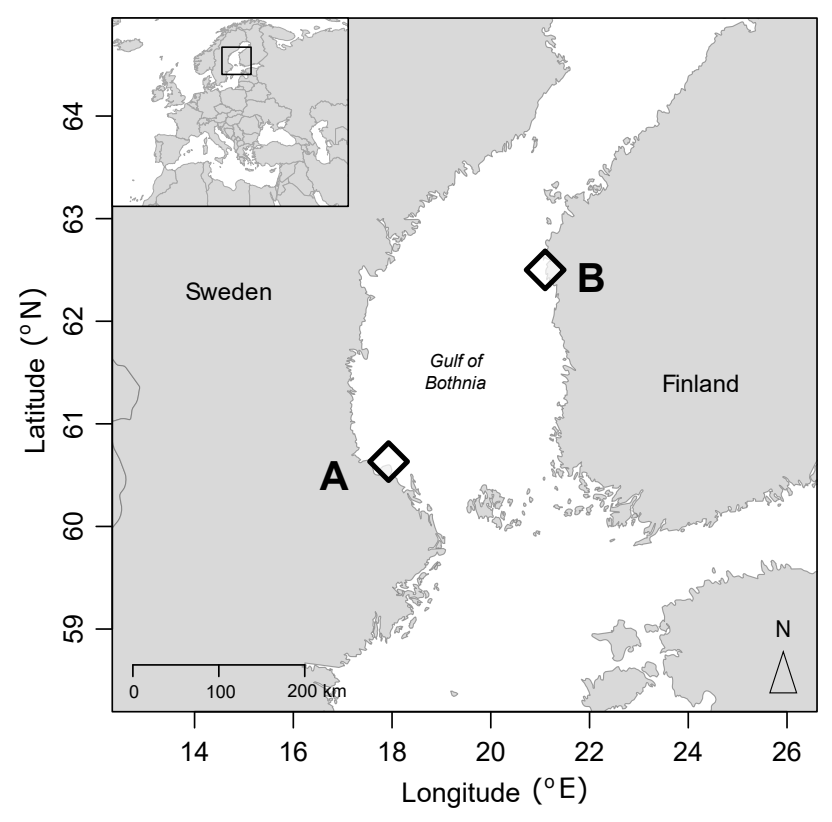

Fig. 1. Location of Caspian Tern breeding colonies in the Gulf of Bothnia of the Baltic Sea. (A) Colony in Sweden on the island of Norra Stenarna, (B) and colony on Gubbstenen in Finland. 
Methods for further discussion of device effects). In 2013 and 2014, loggers were attached using the wing-harness method and in 2016 loggers were fitted using the leg-loop method (Thaxter et al., 2014). Teflon ribbon (2013, 2014, 2016) was used to fasten the loggers, and was sewn together using nylon string and glued at the ends using Loctite 406(c) cyanoacrylate glue. The ringing of Caspian Terns in Sweden was performed under Ringmärkningscentralen permit number 710 (to Lennart Söderlund) and tagging under ethical permit from Malmö-Lunds Djurförsöksetiska Nämnd (M470-12, M72/15). Tagging and handling was in accordance with relevant permits as issued by Finnish authorities (ringing permit: 2604; GPS-harnessing permit: VARELY/115/2015).

\subsection{Data processing}

\subsubsection{Nest-phase demarcation}

The duration of tracking data for each individual was variable (max: 3 years, min: 2 weeks). To improve comparability among the year-samples from each colony, data were filtered to the years with at least six simultaneously-transmitting devices. Since direct observations of nest-phase progression were unavailable for the tagged birds, tracking data was filtered to the period deemed as best representing active nesting (i.e. incubation, brooding, chick-rearing) based on population breeding phenology information and individual mapping of each track. For all but one bird (ID: SER06), the tracking period began with logger attachment during late incubation. For individual SER06, pre-nesting data was clipped by removing data prior to and including the last absence from the colony of greater than $24 \mathrm{~h}$; an additional 7 days after this final absence were also removed, with the assumption that egg-laying does not occur directly upon arrival (Ludwigs \& Becker, 2002).

To identify the end of the nesting period for each individual two different methods were used: for several individuals breeding at Stenarna (ID: 2026, 2027, 2031, 2032, 2033, 2061, 2073, 2086) nest observations from a remote camera were used to identify the date at which the nest failed, or the young fledged. Birds 2027, 2032, and
2033 had their nests predated by a White-tailed Eagle (Halieatus albicilla) several days after logger attachment and since all three individuals re-nested, the tracking data from the second nest attempt were analyzed herein. For the remaining individuals, a colony absence of $>24 \mathrm{~h}$ was considered a failed or fledged nest. In addition, tracking data beyond the median reported nesting duration (i.e. egg-laying to fledging) for Caspian Terns of 60 days (Barlow \& Dowding, 2002) were also excluded. Direct observation of nesting for tracked birds was not practically possible which restricted our ability to attribute tracking data to specific nest phases (e.g., incubation to chick-rearing).

\subsubsection{Time interval standardization \& trip calculation}

Due to differences in the experimental set-up between colony datasets, the time interval at which locations were sampled was heterogeneous. To approximate a standard interval, the data were down-sampled to the lowest common interval of 30 min using custom $\mathrm{R}$ code. To calculate general movement characteristics, data were segmented into discrete foraging trips for each individual, and colony-level averages calculated for each characteristic. A trip was considered a period of greater than 40 min spent beyond a $1 \mathrm{~km}$ colony buffer.

\subsubsection{Geodata and habitat classification}

To investigate the habitat selectivity of nesting Caspian Terns, the aquatic environment surrounding each colony was classified into different types. Seawater was separated into depth intervals $(0-5$, 5-10, 10-20, 20-30, 30-40, $>40 \mathrm{~m}$ ), and since all freshwater bodies in these regions fall within 0-5 $\mathrm{m}$ in depth, a separate category (Inland) was used to distinguish their use.

For the Stenarna colony, bathymetric data at $500 \mathrm{~m}$ horizontal resolution was downloaded from the Baltic Sea Bathymetry Database (http://data.bshc.pro), and for Gubbstenen, $20 \mathrm{~m}$ resolution data was acquired from the Finnish Environmental Institute (http://paikkatieto. 
ymparisto.fi/velmu); these data were respectively aggregated and resampled using nearest bilinear interpolation to $100 \mathrm{~m}$ resolution. Shapefiles of inland waters were downloaded from the Swedish Meteorological Institute and the Finnish National Land Survey, and rasterized to $100 \mathrm{~m}$ resolution. The aforementioned steps were performed using ArcMap10 v.10.5 (ESRI, 2016).

\subsection{Statistical Analyses}

\subsubsection{Daily foraging effort}

The daily foraging effort for each individual was estimated by calculating the total time spent away from the colony (sum of trip durations) and the total distance travelled (sum of total distance per trip). In a linear mixed model framework, each metric of foraging effort was modelled as a function of Julian day of the year (mean-centered) and colony, with individual bird as a random effect to account for the non-independence of observations ( $R$ package ' lme4, Bates et al., 2015). Year was not included in the models as they were unique at each site and only one was available for Gubbstenen. A step-wise model selection procedure was used to determine whether colony, its interaction with day of the year, and random slopes or intercepts produced the most parsimonious and informative model. Information criterion (AIC) were calculated using maximum likelihood for fixed effects and restricted maximum likelihood for random effects. Time spent per day and daily distance travelled were visually inspected to ensure they met model assumptions (Fig. S1-2); daily distance travelled was square root-transformed to meet the assumption of normality (Fig. S2).

\subsubsection{Habitat use}

To quantify patterns of habitat use, Manly's selection ratio with a Type II design was used. In this design, individual habitat use is measured relative to categorical habitat types, and the availability is assumed equal across individuals in the group (Manly et al., 2007), which is an appropriate assumption for colony-breeding birds (Donazar et al., 1993; Tyson et al., 2015). Habitat was considered available within a 'use area' for each colony, and was delineated as the spatial union of $95 \%$ minimum convex polygons calculated around the fixes of each individual (Fig. 4A-C; Jones, 2001). Land was not considered as potential foraging habitat and was therefore omitted from calculation of proportional use and availability.

Terns are aquatic foragers, therefore points with an instantaneous speed of less than $1.5 \mathrm{~m} / \mathrm{s}$ were considered as representing a grounded bird and were filtered out of the dataset (Fig. S3). Then, for each individual, the proportion of off-colony ( $>1 \mathrm{~km}$ from colony center), in-flight fixes over each habitat type were compared to the proportional availability of each type within the colony use area, using the selection ratio formula (Manly et al., 2007). Chi-squared goodness-offit tests were used to test for general selectivity patterns within colonies, testing two null hypotheses: (1) proportional habitat use is identical among individuals $\left(X_{\mathrm{L} 1}^{2}\right),(2)$ and overall use patterns are proportional to availability $\left(X_{\mathrm{L} 2}{ }^{2}\right)$ (Manly et al., 2007). For each colony, mean selection ratios were calculated across individuals for each habitat type, with the resulting confidence intervals reflecting the group-level probability of visitation for each habitat type. Use of a habitat type is proportionate to availability when the $95 \%$ confidence interval encompasses a ratio of 1 , and disproportionate when the variation is above (selected) or below (not selected) this ratio (Manly et al., 2007). Selection ratio calculations were made using the 'adehabitatHS' package (Calenge, 2006) in R (R Core Team, 2020).

\subsubsection{Weekly home range fidelity}

To estimate space use patterns, in-flight tracking data was split into weekly bins for each individual and the $95 \%$ and $50 \%$ utilization distributions (UD), which reflect the probability of occurrence across space (Worton, 1989), were estimated using Kernel Density Estimation, a standard technique (Fig. S4 A-C). A fixed kernel with a smoothing parameter of $1.85 \mathrm{~km}$ was used across all birds, which was calculated as half of the median forward displacement distance between in-flight fixes. 
Next, to assess whether terns show site fidelity to foraging trip home ranges between weeks of the nesting period, a randomization procedure was conducted. The pairwise spatial overlap among all possible combinations of weekly UDs was calculated within each individual, and a mean overlap was calculated for each individual, and then for the year-samples at each colony (i.e. Stenarna 2013, 2014 and Gubbstenen 2016). This grand mean indicates the group-level degree of site fidelity. Overlap was calculated for both the $95 \%$ and $50 \%$ UDs using Bhattacharyaa's affinity (BA), an appropriate index when comparing UD similarity, which ranges from 0 (indicating no overlap) to the maximum UD level compared (i.e., 0.95 for the overlap of $95 \%$ UDs; indicating full overlap and identical shape) (Fieberg \& Kochanny, 2005). To facilitate comparison between the degrees of overlap for the different UD levels, BA values were scaled to 1 .

To test whether individual terns are site faithful, the observed mean overlap was compared to a null distribution for each group, which was produced assuming within-individual overlap is equal to between-individual overlap (Carneiro et al., 2017). Within each year-sample, weeks of tracking data were randomly re-assigned to different individuals. So as to maintain the ordinal nature of the weeks, randomization was only done within weekly bins across individuals (Fig. 2). Pairwise overlap was then calculated within each randomized 'individual.' Since the extents of individual tracking periods were heterogeneous, only week-bins with a minimum of 3 simultaneously-tracked individuals were included, and weeks with fewer than 3 days of tracking data were also excluded (Fig. 2). Individual 2032 was excluded from this analysis as there were only 2 weeks of data available. Randomization was permutated 199 times and the group-level mean calculated for each permutation. The proportion of permutations with a mean overlap less than that of the observed mean overlap was taken as a test of the significance, with the p-value being set by the number of permutations (i.e., 199 randomized permutations plus the observed permutation gives a minimum p-value of 0.005) (Baylis et al., 2017).

\subsubsection{Weekly foraging site fidelity}

To investigate whether foraging site fidelity changes over the season, we identified foraging sites which were revisited for each week. For each

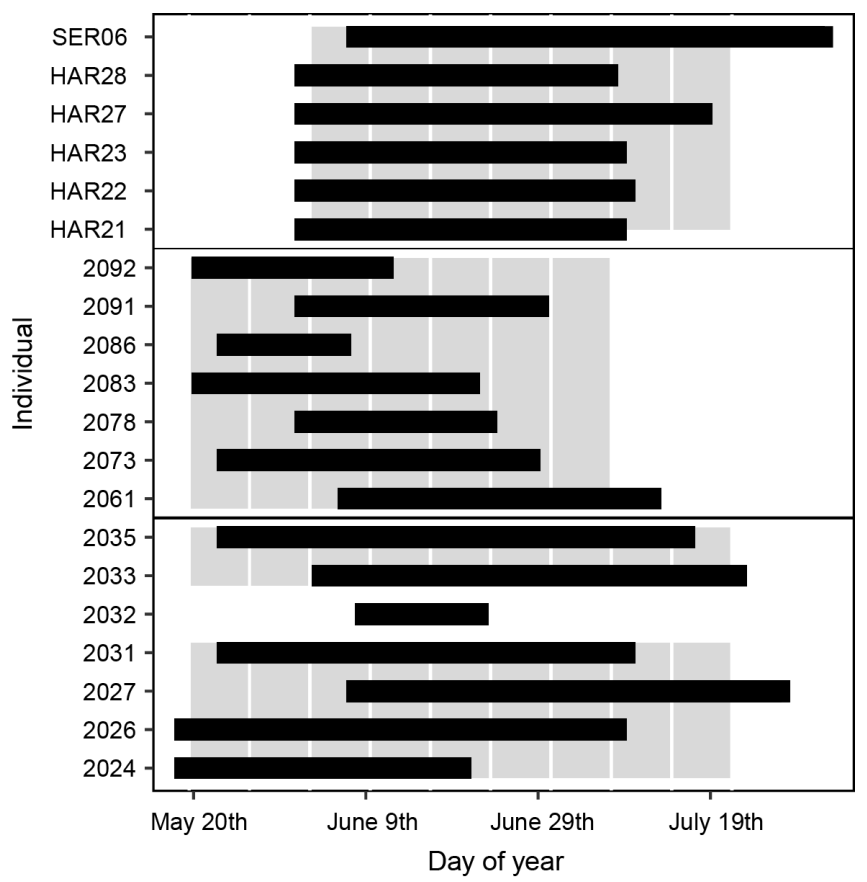

Fig. 2. Tracking periods for individual Caspian Terns tracked with GPS during the breeding season at Stenarna colony in 2013 (bottom) and 2014 (middle), and from Gubbstenen colony in 2016 (top). Black bars represent the extent of tracking data for each individual. The full extent of black bars represents the data used to calculate trip characteristics for each colony, daily foraging effort, and habitat use. Where the black bars overlap grey boxes represent the subset of data used to estimate site fidelity; white vertical lines within the grey boxes signify the weeks of the year, by which the data were partitioned in the randomization procedure testing for foraging site fidelity. 
trip, we defined 'foraging sites' as the most-distant point from the colony, and classified revisits as subsequent trips (in a given week) to locations within $500 \mathrm{~m}$ of a previously-visited site. Next, in a linear mixed-effects framework, we modelled the proportion of revisit trips per week as a function of the relative week of tracking, with individual tern set as a random effect to account for repeated measures (Bates et al., 2015). To quantify whether individuals consistently differed in the degree of site revisitation, we estimated the repeatability of trip revisits per individual using the $\mathrm{R}$ package 'rptR' (Nakagawa \& Schielzeth, 2010). The model was identified using a step-wise model selection procedure (Table S5). Only weeks with 7 or more trips recorded and individuals with at least 4 weeks of tracking were retained ( 7 weeks removed and 16 individuals retained for a total of 94 weeks, IDs: 2032, 2078, 2086, 2092 removed).

\section{Results}

\subsection{Foraging trips and effort}

We recorded a total of 1409 foraging trips at Stenarna (897 in 2013, and 512 in 2014) and 1078 trips at Gubbstenen from across the breeding season. Terns at Stenarna took trips which were $18.6 \mathrm{~km}$ (IQR 6.7) in maximum distance from the colony and of an average total distance travelled of $39.2 \mathrm{~km}$ (IQR 15.5) (Table 1). Foraging trips at Gubbstenen were shorter, with a median maximum distance of $8.5 \mathrm{~km}$ (IQR 5.2) and a total distance travelled of $18.1 \mathrm{~km}$ (IQR 9.6) (Table 1). The duration of foraging trips was variable among individuals at both colonies, but on average terns at Stenarna took trips of $2 \mathrm{~h} 18$ min compared to trips at Gubbstenen which averaged $1 \mathrm{~h} 45$ min in duration. Birds at Stenarna subsequently took fewer trips per day (2.9, SD 1.2) than those breeding at Gubbstenen (4.4, SD 1.4) (Table 1).

The most parsimonious model identified for daily time spent on foraging trips included day of the year but not colony, as a fixed effect, and random intercepts and slope estimated for each individual tern (Table S3A-B). Based on model predictions, we found that the terns at both colonies spent an average of $10 \mathrm{~h} 10 \mathrm{~min}$ (SE $21 \mathrm{~min}$ ) away from the colony each day, which increased significantly as the nesting season progressed by $3.4 \mathrm{~min}$ (SE 1.1) per day (Fig. 3A, Table S4; $d f=16.8, t=2.99, p=0.01, R_{\text {marginal }}^{2}$ $=0.05)$. Individual-level differences accounted for $20 \%$ of the variation in the model $\left(R_{\text {conditional }}^{2}\right.$ $=0.25$ ). For daily foraging distance, the most parsimonious model included day of the year and colony as fixed effects, with random intercepts being estimated for each individual tern (Table S3C-D). We did not identify a significant population-level effect of day of the year on the square root of the total distance travelled per day (Table S4, $d f=701, t=1.39 p=0.17$ ). However, there was a significant difference between the colonies $(d f=17.5, t=4.1, p<0.001)$, and a significant interaction between colony and day of the year $(d f=699.5, t=4.1, p<0.001)$, with birds at Stenarna travelling further per day and having a steeper, positive relationship with day of the year compared to Gubbstenen birds (Fig. $3 \mathrm{~B}$, Table S4). Colony-level fixed effects in the model explained $23 \%$ of the residual variation, with individual-level differences explaining an additional $15 \%\left(R_{\text {marginal }}^{2}=0.23, R_{\text {conditional }}^{2}=0.38\right)$.

Table 1. Foraging trip characteristics of Caspian Terns tracked from breeding colonies in Sweden (Stenarna) and Finland (Gubbstenen). The number of individuals tracked and the total number of trips recorded from each colony are indicated by ' $n(I D)$ ' and ' $n$ (trips)' respectively. Values represent medians of medians per individual and inter-quartile ranges, and means with standard deviation for trips per day. Values in parentheses represent the first and third quartile values.

\begin{tabular}{lllllll}
\hline Group & $\begin{array}{l}\mathrm{n} \\
(\mathrm{ID})\end{array}$ & $\begin{array}{l}\mathrm{n} \\
(\text { trips })\end{array}$ & $\begin{array}{l}\text { Max. distance } \\
(\mathrm{km})\end{array}$ & $\begin{array}{l}\text { Total distance } \\
(\mathrm{km})\end{array}$ & $\begin{array}{l}\text { Duration } \\
(\mathrm{min})\end{array}$ & $\begin{array}{l}\text { Trips } \\
\text { per day }\end{array}$ \\
\hline Gubbstenen & 6 & 1078 & $8.5 \pm 5.2$ & $18.1 \pm 8.6$ & $105(95-114)$ & $4.4+1.4$ \\
Stenarna & 14 & 1409 & $18.6 \pm 6.7$ & $39.2 \pm 15.5$ & $138(120-238)$ & $2.9 \pm 1.2$ \\
\hline
\end{tabular}


A

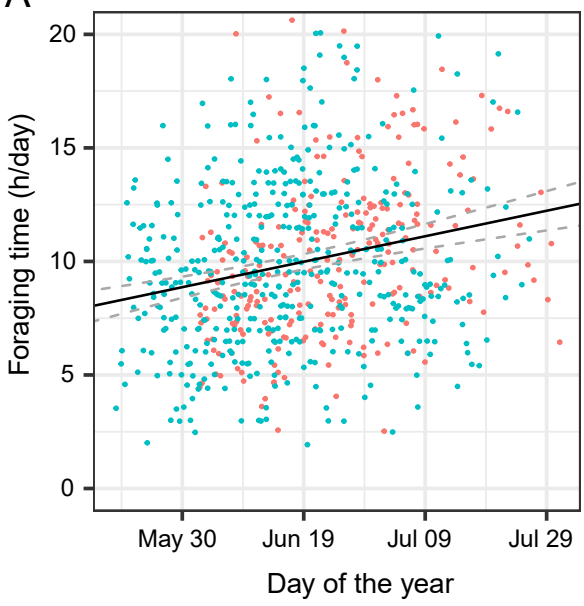

B

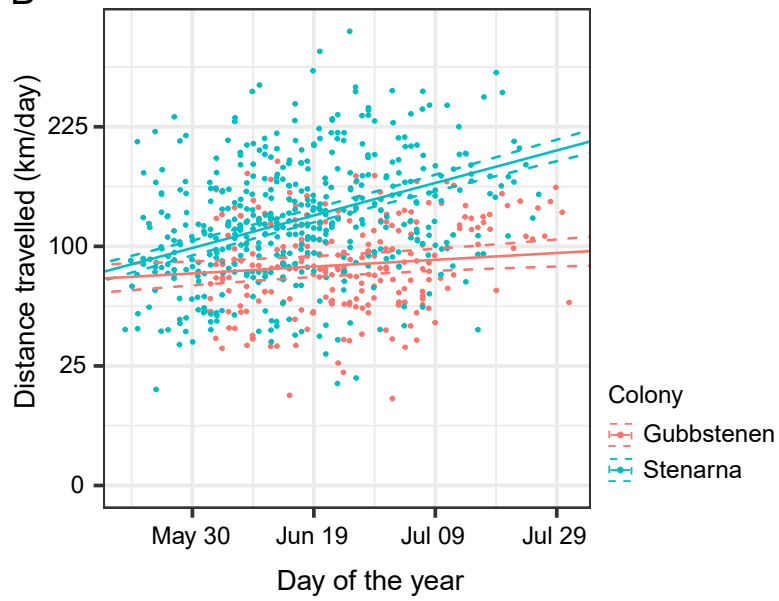

Fig. 3. Association between metrics of daily foraging effort of breeding Caspian Terns and seasonal advancement. (A) The predicted marginal effect of day of the year on daily time spent on foraging trips $\left(R_{\text {marginal }}^{2}=0.05, R_{\text {conditional }}^{2}=\right.$ $0.25, p=0.01$ ) is shown as a black line, with dotted lines representing the $95 \%$ confidence intervals. (B) Colored lines represent the predicted relationship between day of the year and total distance (on square root scale) travelled per day on foraging trips at each breeding colony $\left(R_{\text {marginal }}^{2}=0.23, R_{\text {conditional }}^{2}=0.38, p=0.17\right)$. Lines are split by colony to illustrate that the mean distance travelled per day $(p<0.001)$ and the marginal effect of day of the year $(p<0.001)$ differed significantly between terns breeding at Stenarna and Gubbstenen colonies. (A, B) Colored dots represent observed daily estimates of foraging time and distance travelled for individuals from Stenarna and Gubbstenen breeding colonies. Predicted relationships were derived from linear mixed effects models (Table S3-4).

\subsection{Habitat use}

Tracked Caspian Terns visited waters between $0-40 \mathrm{~m}$ in depth, yet when the relative availability and relative use of depth intervals were taken into account the only depth range selected for foraging in seawater habitat was $0-5 \mathrm{~m}$ deep water (Fig. 4). Habitat use was significantly non-random (Table S2; Stenarna: $d f=84, X_{\mathrm{L} 2}{ }^{2}=$ 13,493, $p<0.001$; Gubbstenen: $d f=18, X_{\mathrm{L} 2}^{2}=$ 4454, $p<0.001)$ and differed among individuals at both colonies (Table S2; Stenarna: $d f=78, X_{\mathrm{L} 1}{ }^{2}$ = 3412, $p<0.001$; Gubbstenen: $d f=15, X_{\mathrm{L} 1}{ }^{2}=$ 173, $p<0.001)$. Freshwater areas represented only $4 \%$ and $1 \%$ of the water area available at Stenarna and Gubbstenen respectively, and were used in proportion to availability at both colonies. However, selectivity at the individual level was highly variable, with certain individuals selecting inland freshwaters and others not (Fig. 4D-F, Table S2).

\subsection{Weekly foraging site fidelity}

For birds from Stenarna, the mean overlap of within-individual weekly home ranges was 0.44 (SD 0.008, 95\% UD) and 0.30 (SD 0.01, 50\% UD) in 2013, and 0.44 (SD 0.03, 95\% UD) and 0.23 (SD 0.03, 50\% UD) in 2014. At Gubbstenen, the mean overlap was 0.70 (SD $0.1,95 \%$ UD), and 0.36 (SD 0.02, 50\% UD). The observed mean overlap was significantly higher than the null distribution in all three year-samples, for both the 95\% UD (S-2013: $p=0.005, \mathrm{~S}-2014: p=0.005$; G-2016: $p=0.005)$ and the 50\% UD (S-2013: $p$ $=0.005, \mathrm{~S}-2014: p=0.005 ; \mathrm{G}-2016: p=0.005)$ (Fig. 5A), respectively, indicating that individuals overlap spatially with areas used in prior weeks of foraging more than expected by chance.

We estimated that terns revisited foraging sites every $2 \mathrm{~d} 11.5 \mathrm{~h}$ (mean, SD $6 \mathrm{~h}$ ) per week, and found that the maximum period over which a tern re-visited the same site was $51 \mathrm{~d}$ and 6 h. The most parsimonious model identified to explain foraging site re-visitation rate included day of the year as a fixed effect with random 
A

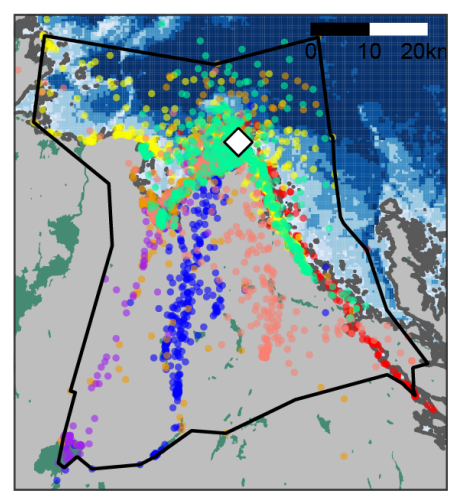

B

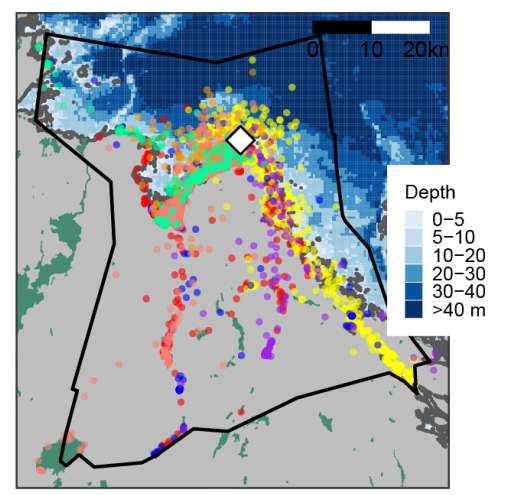

C

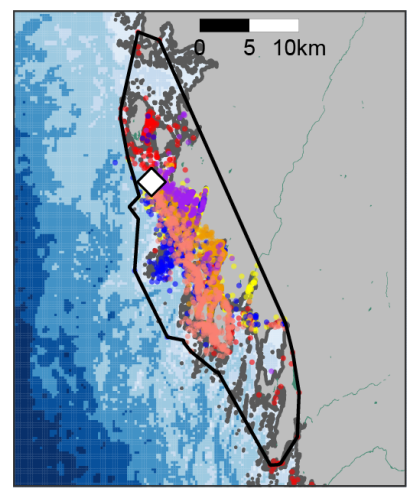

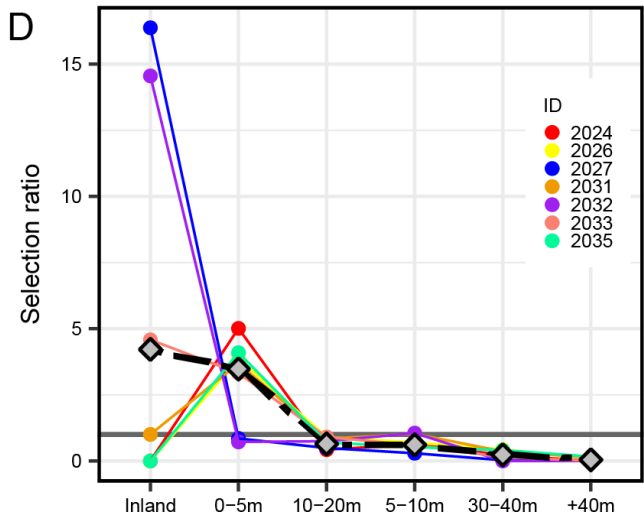

E

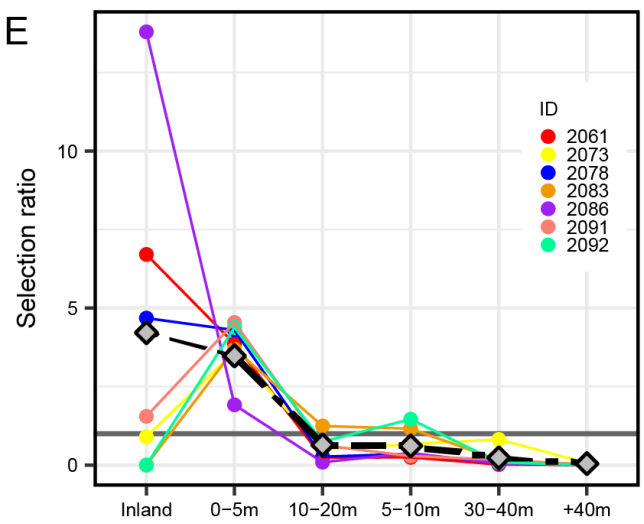

F

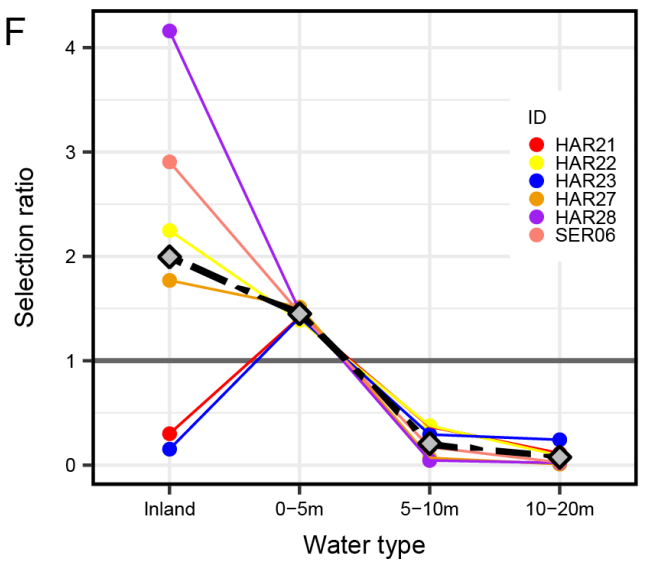

Fig. 4. Tracked movements and habitat selection of Caspian Terns during breeding in the Baltic Sea. Movements of individual terns from the breeding colonies of Stenarna in (A) 2013, (B) 2014, and Gubbstenen in (C) 2016. Dots represent GPS-fixes of birds during flight; each color represents a different individual. Polygon outlines (black) represent the $95 \%$ minimum convex polygons within which the availability of water types were calculated at each colony. Seawater bathymetry is scaled from white to dark blue and inland waters are green-blue. Patterns of habitat selectivity of terns tracked from Stenarna in 2013 (D) and 2014 (E) and Gubbstenen in 2016 (F). Habitat use was quantified as a selection ratio, which is the proportional use of a water type over its relative availability around the colony. Grey diamonds represent the group-level mean selection ratio for each water type, of which ratios above and below 1 respectively indicate positive and negative selectivity. Water types are ranked from left to right in order of highest to lowest mean selectivity at the group level. Colored dots and lines signify the habitat use pattern of individual terns. Year-samples from Stenarna were analyzed together and are shown separately for clarity. 
A

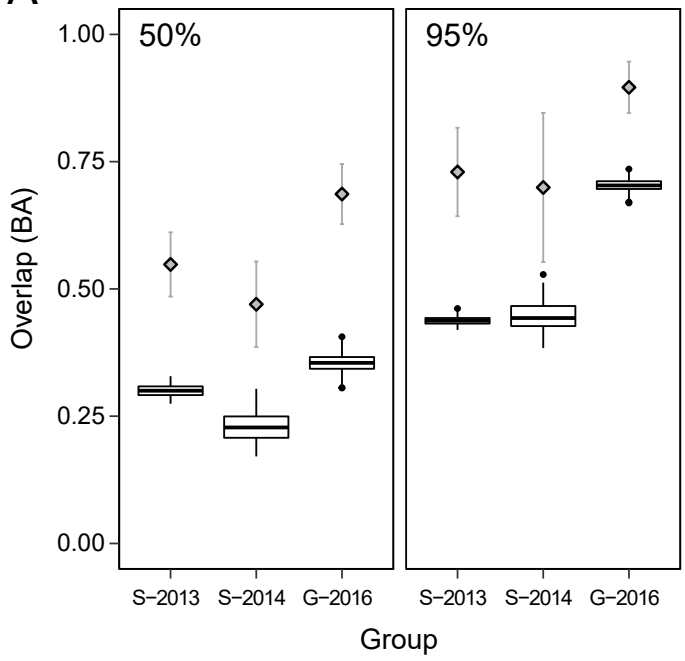

B

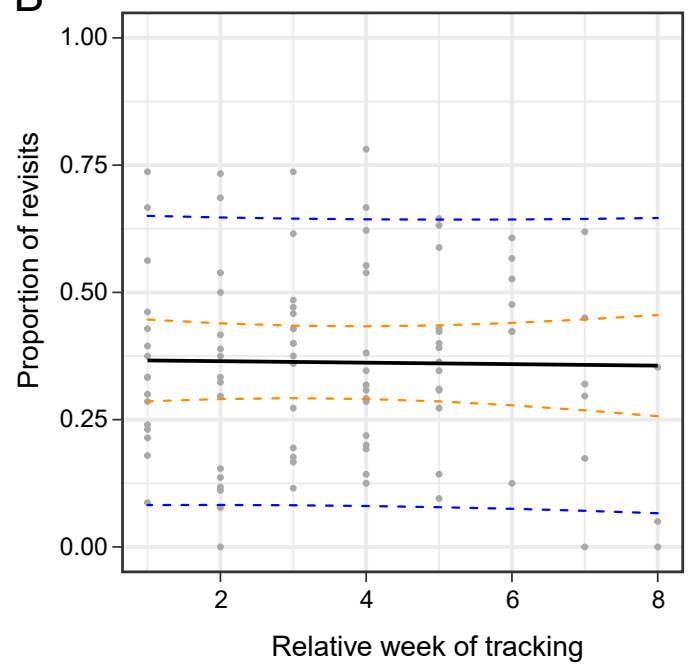

Fig. 5. Foraging site fidelity of Caspian Terns during the breeding season. (A) Resulting distributions from randomization procedure testing whether Caspian Terns tracked from Stenarna (S-2013, S-2014), and Gubbstenen (G-2016) were more faithful to foraging sites than expected at random. Fidelity was estimated as between-week overlap of $50 \%$ (left panel) and $95 \%$ (right panel) utilization distribution areas, where overlap was quantified using an index of distribution similarity (Bhattacharyaa's affinity). Grey diamonds (mean) and error bars (1 SD) represent the observed withinindividual overlap for each tracking sample. Boxes signify the distribution of randomized grand mean overlaps across 199 permutations assuming between-individual overlap is equal to within-individual overlap. The lack of overlap between distributions indicates the observed pattern differs significantly from random. (B) Weekly foraging site revisitation rate and advancing season. The predicted marginal effect of week of the season (relative to when each individual was tracked) on the rate at which terns revisit foraging sites is shown as a black line. The orange dotted line represents the $95 \%$ confidence interval around the mean effect, and the blue line represents the prediction interval, illustrating the large effect of among-individual variation in the linear-mixed effects model.

intercepts estimated for each individual tern (Table S5). The model-estimated weekly change in the proportion of trips which are revisits was -0.001 min (SE 0.007), which was not significant (Fig. 5B, Table S6; $d f=80.2, t=-0.185, p=$ $0.85, R_{\text {marginal }}^{2}=0.0002$ ). However the variation in the estimated mean effect does not discount a possible effect. Individual differences accounted for $47 \%$ of the variation explained by the model (Fig. 5B, $R_{\text {conditional }}^{2}=0.47$ ), and individual terns were significantly repeatable in the rate at which they revisited sites among weeks $(R=0.475, S E=$ $0.118, p<0.001)$.

\section{Discussion}

Habitat use and foraging strategies are central to the foraging ecology of aquatic birds. Here, we revealed aspects of the breeding season foraging ecology of Caspian Terns in the little-studied population of the Baltic Sea. We found that Caspian Terns at two breeding colonies increased their daily foraging effort from late incubation through chick-rearing by spending more time on foraging trips, and that changes in total distance travelled differed at the colony level. Tracked Caspian Terns selected shallow coastal waters, and when available, inland lakes for foraging. We showed that individuals differ in their habitat use patterns and are highly site faithful, maintaining the same foraging areas throughout the breeding season, despite changes in effort. These results further understanding of the roles of habitat availability and individual site fidelity in the foraging ecology of this widespread species (Dunlop \& McNeill, 2017; Koli \& Soikkeli, 1974; Lyons et al., 2005; McNicholl, 1990).

As we were not able not distinguish between different in-flight behavioral states (e.g., active 
foraging, transiting), the habitat use patterns described here also reflect the habitats the terns passed over in transit (Bennison et al., 2018). Nevertheless, given that foraging behavior in this species is characterized by sinuous movement within a restricted area, much of the habitat use signal we report likely represent true foraging habitat selection. Our results support the general understanding of this species as a coastal and inland forager (Cramp, 1985; Dunlop \& McNeill, 2017). It is apparent from our selection ratio calculations (Fig. 4D-F) that certain individuals visit lakes while others use only coastal waters (Fig. 4D-F). Whether this represents true habitat specialization remains unclear, however as all individuals which visited lakes also used coastal areas, it may more likely represent spatial fidelity.

Our finding that terns re-use foraging areas more than expected by chance, and even revisit the same sites throughout the season is, to the best of our knowledge, the first quantitative evidence of foraging site fidelity in this species. Individual foraging site specialization has been reported for an increasing number of taxa (e.g., Baylis et al., 2017; Drury \& Smith, 1968; Hillen et al., 2009; Patrick \& Weimerskirch, 2014) and that Caspian Terns also display this behavior suggests that site familiarity is an important part of their foraging strategy (Piper, 2011). Breeding Common Terns (Sterna hirundo) are often site-faithful to the point of territoriality (Nisbet, 1983). Although this agonistic behavior has also been reported for Caspian Terns (McNicholl, 1990), it remains unverified as a common strategy. Our observation of site fidelity, combined with a certain degree of spatial and habitat segregation (Fig. 4), indicates that intra-specific competition may indeed influence colony-level space use patterns in this species (Davoren et al., 2003; Sánchez et al., 2018).

We found a difference in foraging range between our study colonies, with the values from the Stenarna colony being similar to published averages from other Caspian Tern populations (Anderson et al., 2007; Oppel et al., 2018) and the maximum distances reached at Gubbstenen being lower. The smaller sample from Gubbstenen may not fully represent colony-level variation, however given that individuals are site faithful throughout the season and variation in trip characteristics was not large (Table 1), this suggests a real difference between the colonies in this respect. The distribution of preferred foraging habitats (shallow coastal water and freshwater) differed between the colonies, which may have affected the distances birds had to travel to reach foraging sites. At both colonies, we found that the daily time spent on trips increased from late incubation through chick-rearing, which could reflect increasing energetic demands of chicks or deteriorating prey availability (Elliott et al., 2009; Humphreys et al., 2006). The total distance travelled per day at Stenarna also increased sharply with time, suggesting that competition there may have been more acute as the season progresses than at Gubbstenen. Stenarna hosts around $40 \%$ more breeding pairs than Gubbstenen, which could also contribute to differences in the resource competition (Jovani et al., 2016). Terns are known to use foraging trips as opportunities for self-maintenance (e.g., preening, resting), therefore changes in daily off-colony movements could in part reflect release from responsibility when chicks gain thermoregulatory independence (Palestis \& Burger, 1998).

Despite changes in daily foraging trip movements throughout nesting, we found no support for general changes in the degree of site fidelity. Instead, we found substantial among-individual variation in foraging site re-visitation rates and that these differences were consistent across the season. This indicates that as foraging effort changes individuals maintain their strategies, whether that means frequent re-use of the same few sites or more exploratory search behavior. This represents a novel finding regarding Caspian Terns, however recent work has implicated the roles of individual condition, quality, and personality on foraging behavior in a number of seabird species (Geary et al., 2019; Patrick \& Weimerskirch, 2014). By combining further tracking with direct observation of nest progression and outcomes, and prey types brought to the nest (e.g., Anderson et al., 2007) future work could reveal the drivers of the foraging strategies described here and clarify whether foraging site fidelity persists across seasons and is associated with habitat specialization in this and similar species. 


\section{Konsekvent födosöksbeteende hos en hotad Östersjöhäckande havsfågel}

Födosöksstragier och habitatspreferenser är viktiga begrepp för att förstå förändringar av djurpopulationer och hur dessa populationer kan bevaras. I denna studie undersökte vi rörelsemönster hos skräntärnor (Hydroprogne caspia) i Östersjön under häckningstiden som tills nu studerats endast till begränsad del. Vi analyserade data från GPS-sändare för 20 individer från två häckningskolonier, en i Sverige och en i Finland. Här beskriver vi de egenskaper som karaktäriserar de dagliga födosöksturerna till och från kolonierna, i vilken typ av vatten de söker föda (vattendjup och insjöar), och i vilken utsträckning individerna använder sig av samma födosöksplatser under hela häckningsperioden. Den dagliga tiden som tärnorna är borta från kolonin för att söka föda ökar signifikant under häckningsperioden. Dessutom verkar kolonierna skilja sig åt angående de dagliga distanserna som tärnorna rör sig för att söka föda. Häckande tärnor väljer att söka föda främst $\mathrm{i}$ grunda vatten $(0-5 \mathrm{~m}$ djup), medan vissa individer sökte föda i insjöar. I studien visar vi för första gången att skräntärnor är trogna specifika födosöksplatser under hela häckningen, men också att individer har olika strategier och att individerna är konsekventa $\mathrm{i}$ de strategier som de använder sig av. Resultaten fyller viktiga kunskapsluckor för denna hotade skräntärnepopulation som häckar i Östersjön, och studien bidrar med ny information om födosöksekologin hos individer av den globalt vittspridda art

Acknowledgements. For the various tasks associated with the capture, tagging, monitoring of the Caspian Terns as well as transport to and from Stenarna many thanks go to Natalie Isaksson, Ewa Karaszewska, Kjell Holmkvist, Lennart Söderlund, Willem Bouten, Arne Andersson, Johan Bäckman, Giuseppe Bianco, and last but not least to the terns themselves. This work was supported by grants from the Swedish Research Council (621-20105584, 621-2013-4361) and Lund University to SA and the JSPS (the Japan Society for the Promotion of Science) Postdoctoral Fellowships for Research Abroad (25-360) to KS. This study received support from the Centre for Animal Movement Research (CAnMove) funded by a Linnaeus grant from the Swedish Research Council (349-2007-8690) and Lund University, the Swedish studies done by BirdLife Sweden was funded from Alvins
Fund (the Swedish Environmental Protection Agency), Lindbergs foundation (Sweden), WWF Sweden and by BirdLife Sweden itself. Field work in Finland was funded by Ingrid, Margit and Henrik Höijers donationsfond II (SLS) (34-1605-2) and Swedish Cultural Foundation in Finland (16/2871), all to PB.

Conflict of Interest. Authors report no conflicts of interest.

\section{References}

Anderson, S. K., Roby, D. D., Lyons, D. E., \& Collis, K. 2007: Relationship of Caspian tern foraging ecology to nesting success in the Columbia River estuary, Oregon, USA. - Estuarine, Coastal and Shelf Science 73: 3-4, 447-456. https://doi.org/10.1016/j.ecss.2007.02.006

Augé, A.A., Dias, M.P., Lascelles, B., Baylis, A.M.M., Black, A., Boersma, P.D., Catry, P., Crofts, S., Galimberti, F., Granadeiro, J.P., Hedd, A., Ludynia, K., Masello, J.F., Montevecchi, W., Phillips, R.A., Pütz, K., Quillfeldt, P., Rebstock, G.A., Sanvito, S., Staniland, I.J., Stanworth, A., Thompson, D., Tierney, M., Trathan, P.N., Croxall, J.P. 2018: Framework for mapping key areas for marine megafauna to inform Marine Spatial Planning: The Falkland Islands case study. - Marine Policy 92: 61-72. https://doi.org/10.1016/j.marpol.2018.02.017

Barlow, M. L., \& Dowding, J. E. 2002: Breeding biology of Caspian terns (Sterna caspia) at a colony near Invercargill, New Zealand. - The Ornithological Society of New Zealand 49: 76-90.

Bates, D., Mächler, M., Bolker, B., \& Walker, S. 2015: Fitting Linear Mixed-Effects Models Using lme4. — Journal of Statistical Software 67(1): 1-48. https://doi. org/10.18637/jss.v067.i01

Baylis, A. M. M., Orben, R. A., Costa, D. P., Tierney, M., Brickle, P., \& Staniland, I. J. 2017: Habitat use and spatial fidelity of male South American sea lions during the nonbreeding period. - Ecology and Evolution 7(11): 3992-4002. https://doi.org/10.1002/ece3.2972

Bennison, A., Bearhop, S., Bodey, T. W., Votier, S. C., Grecian, W. J., Wakefield, E. D., Hamer, K. C., \& Jessopp, M. 2018: Search and foraging behaviors from movement data: A comparison of methods. - Ecology and Evolution 8(1): 13-24. https://doi.org/10.1002/ ece3.3593

Birt, V. L., Birt, T. P., Goulet, D., Cairns, D. K., \& Montevecchi, W. A. 1987: Ashmole's halo: Direct evidence for prey depletion by a seabird. - Marine Ecology Progress Series 40(3): 205-208.

Calenge, C. 2006: The package "adehabitat" for the R software: A tool for the analysis of space and habitat use by animals. - Ecological Modelling 197(3): 516-519. https://doi.org/10.1016/j.ecolmodel.2006.03.017

Carneiro, A. P. B., Bonnet-Lebrun, A.-S., Manica, A., Staniland, I. J., \& Phillips, R. A. 2017: Methods for 
detecting and quantifying individual specialisation in movement and foraging strategies of marine predators. - Marine Ecology Progress Series 578: 151-166. https://doi.org/10.3354/meps12215

Ceia, F. R., Paiva, V. H., Fidalgo, V., Morais, L., Baeta, A., Crisóstomo, P., Mourato, E., Garthe, S., Marques, J. C., \& Ramos, J. A. 2014: Annual and seasonal consistency in the feeding ecology of an opportunistic species, the yellow-legged gull Larus michahellis. - Marine Ecology Progress Series 497: 273-284. https://doi. org/10.3354/meps 10586

Craig, D. P., \& Larson, K. 2017: Migratory Connectivity of North American Caspian Tern (Hydroprogne caspia) Populations. — Waterbirds 40(1): 58-62. https://doi. org/10.1675/063.040.0108

Cramp, S. 1985: The Birds of the Western Palearctic, Volume 4: Terns to Woodpeckers. - Oxford Univ Press.

Davoren, G. K., Montevecchi, W. A., \& Anderson, J. T. 2003: Distributional patterns of a marine bird and its prey: Habitat selection based on prey and conspecific behaviour. - Marine Ecology Progress Series 256: 229 242.

Donazar, J. A., Negro, J. J., Hiraldo, F., \& Hiraldo, F. 1993: Foraging Habitat Selection, Land-Use Changes and Population Decline in the Lesser Kestrel Falco naumanni. - Journal of Applied Ecology 30(3): 515522. https://doi.org/10.2307/2404191

Drury, W. H., \& Smith, W. J. 1968: Defense of Feeding Areas by Adult Herring Gulls and Intrusion by Young. Evolution 22(1): 193-201. https://doi.org/10.1111/ j.1558-5646.1968.tb03462.x

Dunlop, J. N., \& McNeill, S. 2017: Local movements, foraging patterns, and heavy metals exposure in Caspian Terns Hydroprogne caspia breeding on Penguin Island, Western Australia. — Marine Ornithology 45: 115-120.

Elliott, K. H., Woo, K. J., Gaston, A. J., Benvenuti, S., Dall'Antonia, L., \& Davoren, G. K. 2009: Central-Place Foraging in an Arctic Seabird Provides Evidence for Storer-Ashmole's Halo. — The Auk 126(3): 613-625. https://doi.org/10.1525/auk.2009.08245

Fieberg, J., \& Kochanny, C. O. 2005: Quantifying HomeRange Overlap: The Importance of the Utilization Distribution. - The Journal of Wildlife Management 69(4): 1346-1359.

Geary, B., Walter, S. T., Leberg, P. L., \& Karubian, J. 2019. Condition-dependent foraging strategies in a coastal seabird: Evidence for the rich get richer hypothesis. Behavioral Ecology 30(2): 356-363.

HELCOM Red List Bird Expert Group. 2013: HELCOM 2013-H. caspia-Fact Sheet. HELCOM. www. helcom.fi

Hillen, J., Kiefer, A., \& Veith, M. 2009: Foraging site fidelity shapes the spatial organisation of a population of female western barbastelle bats. - Biological Conservation 142(4): $\quad 817-823$. $\quad$ https://doi.org/10.1016/j. biocon.2008.12.017

Humphreys, E. M., Wanless, S., \& Bryant, D. M. 2006:
Stage-dependent foraging in breeding black-legged kittiwakes Rissa tridactyla: Distinguishing behavioural responses to intrinsic and extrinsic factors. - Journal of Avian Biology 37(5): 436-446. https://doi.org/10.1111/ j.2006.0908-8857.03594.x

Irons, D. B. 1998. Foraging area fidelity of individual seabirds in relation to tidal cycles and flock feeding. - Ecology 79(2): 647-655. https://doi.org/10.1890/00129658(1998)079[0647:FAFOIS]2.0.CO;2

Jones, J. 2001: Habitat Selection Studies in Avian Ecology: A Critical Review. — The Auk 118(2): 557. https://doi. org/10.1642/0004-8038(2001)118[0557:HSSIAE]2.0. $\mathrm{CO} ; 2$

Jovani, R., Lascelles, B., Garamszegi, L. Z., Mavor, R., Thaxter, C. B., \& Oro, D. 2016: Colony size and foraging range in seabirds. - Oikos 125(7): 968-974. https://doi. org/10.1111/oik.02781

Koli, L., \& Soikkeli, M. 1974: Fish prey of breeding Caspian terns in Finland. - Annales Zoologici Fennici 11(4): 304-308.

Ludwigs, J. D., \& Becker, P. H. 2002: The hurdle of recruitment: Influences of arrival date, colony experience and sex in the Common Tern Sterna hirundo. - Ardea 90(3): 389-399.

Lyons, D. E., Roby, D. D., \& Collis, K. 2005: Foraging Ecology of Caspian Terns in the Columbia River Estuary, USA. - Waterbirds 28(3): 280-291. https://doi. org/10.1675/1524-4695(2005)028[0280:FEOCTI]2.0. $\mathrm{CO} ; 2$

Lyons, D. E., Roby, D. D., \& Collis, K. 2007: Foraging Patterns of Caspian Terns and Double-crested Cormorants in the Columbia River Estuary. - Northwest Science 81(2): 91-103. https://doi.org/10.3955/0029344X-81.2.91

Manly, B. F., McDonald, L., Thomas, D., McDonald, T. L., \& Erickson, W. P. 2007: Resource Selection by Animals: Statistical Design and Analysis for Field Studies. Springer Science \& Business Media.

McNicholl, M. K. 1990: Temporary Feeding Territories among Caspian Terns. - Colonial Waterbirds: 13(2), 133-135. https://doi.org/10.2307/1521580

Nakagawa, S., \& Schielzeth, H. 2010: Repeatability for Gaussian and non-Gaussian data: A practical guide for biologists. - Biological Reviews 85(4): 935-956. https://doi.org/10.1111/j.1469-185X.2010.00141.x

Nisbet, I. C. T. 1983: Territorial Feeding by Common Terns. - Colonial Waterbirds 6: 64-70. https://doi. org/10.2307/1520968

Norberg, R. A. 1977: An Ecological Theory on Foraging Time and Energetics and Choice of Optimal FoodSearching Method. - Journal of Animal Ecology 46(2): 511-529. https://doi.org/10.2307/3827

Olsson, O., \& Bolin, A. 2014: A model for habitat selection and species distribution derived from central place foraging theory. - Oecologia 175(2): 537-548. https:// doi.org/10.1007/s00442-014-2931-9

Oppel, S., Bolton, M., Carneiro, A.P.B., Dias, M.P., Green, 
J.A., Masello, J.F., Phillips, R.A., Owen, E., Quillfeldt, P., Beard, A., Bertrand, S., Blackburn, J., Boersma, P.D., Borges, A., Broderick, A.C., Catry, P., Cleasby, I., Clingham, E., Creuwels, J., Crofts, S., Cuthbert, R.J., Dallmeijer, H., Davies, D., Davies, R., Dilley, B.J., Dinis, H.A., Dossa, J., Dunn, M.J., Efe, M.A., Fayet, A.L., Figueiredo, L., Frederico, A.P., Gjerdrum, C., Godley, B.J., Granadeiro, J.P., Guilford, T., Hamer, K.C., Hazin, C., Hedd, A., Henry, L., Hernández-Montero, M., Hinke, J., Kokubun, N., Leat, E., Tranquilla, L.M., Metzger, B., Militão, T., Montrond, G., Mullié, W., Padget, O., Pearmain, E.J., Pollet, I.L., Pütz, K., Quintana, F., Ratcliffe, N., Ronconi, R.A., Ryan, P.G., Saldanha, S., Shoji, A., Sim, J., Small, C., Soanes, L., Takahashi, A., Trathan, P., Trivelpiece, W., Veen, J., Wakefield, E., Weber, N., Weber, S., Zango, L., Daunt, F., Ito, M., Harris, M.P., Newell, M.A., Wanless, S., González-Solís, J., Croxall, J. 2018: Spatial scales of marine conservation management for breeding seabirds. — Marine Policy 98: 37-46. https://doi.org/10.1016/j. marpol.2018.08.024.

Palestis, B. G., \& Burger, J. 1998: Evidence for social facilitation of preening in the common tern. - Animal Behaviour 56(5): 1107-1111. https://doi.org/10.1006/ anbe.1998.0907

Patrick, S. C., \& Weimerskirch, H. 2014: Personality, Foraging and Fitness Consequences in a Long Lived Seabird. - PLOS ONE 9(2), e87269. https://doi. org/10.1371/journal.pone.0087269

Piper, W. H. 2011: Making habitat selection more "familiar": A review. - Behavioral Ecology and Sociobiology 65(7): 1329-1351. https://doi.org/10.1007/s00265-011$1195-1$

R Core Team. 2020: R: A Language and Environment for Statistical Computing. R Foundation for Statistical Computing. https://www.R-project.org/

Ricklefs, R. E. 1990: Seabird Life Histories and the Marine Environment: Some Speculations. - Colonial Waterbirds 13(1): 1-6. https://doi.org/10.2307/1521414

Sánchez, S., Reina, R., Kato, A., Ropert-Coudert, Y., Cavallo, C., Hays, G., \& Chiaradia, A. 2018: Within-colony spatial segregation leads to foraging behaviour variation in a seabird. - Marine Ecology Progress Series 606:

\section{5-230. https://doi.org/10.3354/meps12764}

Sirdevan, J. E., \& Quinn, J. S. 1997: Foraging Patterns of Caspian Terns (Sterna caspia) Determined Using RadioTelemetry. - Colonial Waterbirds 20(3): 429-435. https://doi.org/10.2307/1521593

Thaxter, C. B., Ross-Smith, V. H., Clark, J. A., Clark, N. A., Conway, G. J., Marsh, M., Leat, E. H. K., \& Burton, N. H. K. 2014: A trial of three harness attachment methods and their suitability for long-term use on Lesser Blackbacked Gulls and Great Skuas. - Ringing \& Migration 29(2): 65-76. https://doi.org/10.1080/03078698.2014.99 5546

Torres, L. G., Sutton, P. J. H., Thompson, D. R., Delord, K., Weimerskirch, H., Sagar, P. M., Sommer, E., Dilley, B. J., Ryan, P. G., \& Phillips, R. A. 2015: Poor Transferability of Species Distribution Models for a Pelagic Predator, the Grey Petrel, Indicates Contrasting Habitat Preferences across Ocean Basins. - PLOS ONE 10(3), e0120014. https://doi.org/10.1371/journal.pone.0120014

Tyson, C., Shamoun-Baranes, J., Van Loon, E. E., Camphuysen, K. (C. J. ), \& Hintzen, N. T. 2015: Individual specialization on fishery discards by lesser black-backed gulls ( Larus fuscus ). - ICES Journal of Marine Science: Journal Du Conseil 72(6): 1882-1891. https://doi.org/10.1093/icesjms/fsv021

Wakefield, E. D., Cleasby, I. R., Bearhop, S., Bodey, T. W., Davies, R. D., Miller, P. I., Newton, J., Votier, S. C., \& Hamer, K. C. 2015: Long-term individual foraging site fidelity - Why some gannets don't change their spots. -Ecology 96(11): 3058-3074. https://doi. org $/ 10.1890 / 14-1300.1$

Wakefield, E. D., Phillips, R. A., \& Matthiopoulos, J. 2009: Quantifying habitat use and preferences of pelagic seabirds using individual movement data: A review. Marine Ecology Progress Series 391: 165-182. https:// doi.org/10.3354/meps08203

Weimerskirch, H. 2007: Are seabirds foraging for unpredictable resources? - Deep Sea Research Part II: Topical Studies in Oceanography 54(3): 211-223. https://doi.org/10.1016/j.dsr2.2006.11.013

Worton, B. J. 1989: Kernel Methods for Estimating the Utilization Distribution in Home-Range Studies. Ecology 70(1):164-168.https://doi.org/10.2307/1938423

\section{Online supplementary material}

The supplementary material includes extended methods, as well as figures (Fig. S1-S5) and tables (Table S1-S6) to provide more context to the main analysis. 